\title{
HONGOS COMESTIBLES SILVESTRES COLECTADOS EN LA X REGION DE CHILE
}

\section{(Wild eatable mushrooms collected in the X Region of Chile)}

\author{
Eduardo Valenzuela F. \\ Universidad Austral de Chile, Facultad de Ciencias, \\ Instituto de Microbiología. Casilla 167. Valdivia - Chile.
}

Palabras claves: Hongos silvestres, comestibles, taxonomía, Chile. Key word: Wild mushrooms, eatable, taxonomy, Chile.

RESUMEN

Se reportan 30 especies de hongos silvestres comestibles (autóctonos y alóctonos), Basidiomycota y Ascomycota que fructifican en restos vegetales, bosques nativos, plantaciones forestales, parques, jardines $y$ praderas de la X Región de Chile. Se entrega una descripción macro-microscópica de ellos, se comentan sus aspectos ecológicos y distribución. Además, se da una lista de los Basidiomycota silvestres comestibles que fructifican en otras Regiones del país. En Chile existirían aproximadamente 53 especies de hongos silvestres comestibles. En la zona de Valdivia es posible recolectar unas 30 especies distintas de éstos, destacando entre los apetecidos por la población local: Agaricus campestris (champigñon de campo), A. macrosporus (champiñon), Armillariella montagnei (pique), Boletus loyo (loyo), Grifola gargal (gargal), Ramaria flava var. subtilis (changle), Gyromytra cf esculenta (chicharrón de campo) y varias especies de Cyttaria (dihueñe, pinatra, llaullau). De los hongos silvestres presentes en Chile, por su excelente sapidez y demanda en el mercado internacional, destacan: Agaricus arvensis, Lactarius deliciosus, Macrolepiota bonaerense, Suillus luteus, Volvariella especiosa, Xerocomus chrysenteron $y$ varias especies de Morchella.

\section{INTRODUCCION}

Lazo (2001), señala para Chile 20 especies de hongos silvestres de probada comestibilidad, pero entre los hábitos alimenticios de la población chilena, no está incorporada una cultura micófaga y la mayoría desconoce los hongos silvestres comestibles, éstos son más apetecidos por las poblaciones rurales o indígenas del país. El ciudadano urbano chileno consume carpóforos de hongos esporádicamente y éstos corresponden a las espe-
Thirty species of wild eatable mushrooms (autochthonous and exotic) Basidiomycota and Ascomycota that fructify in vegetal remains, native forests, forest plantations, parks, gardens and, prairies of the $X$ Region of Chile are reported. A macro-microscopic description of them is presented and their ecological aspects and distribution are commented. Besides, a list of those wild eatable Basidiomycota that fructify in other Regions of the country is included. About 53 species of wild eatable mushrooms are considered to exist in Chile. In the area of Valdivia it is possible to collect 30 different species from the latter, being the most wanted within the local population:Agaricus campestris (champigñon de campo), A. macrosporus (champigñon), Armillariella montagnei (pique), Boletus loyo (loyo), Grifola gargal (gargal), Ramaria flava var. subtilis (changle), Gyromytra cf. esculenta (chicharrón de campo) and several species of Cyttaria (dihueñe, pinatra,llaullau). Among wild mushrooms now available in Chile and which stand out for their flavour and demand in the international market, we can mention: Agaricus arvensis, Lactarius deliciosus, Macrolepiota bonaerense, Suillus luteus, Volvariella especiosa, Xerocomus chrysenteron and several species of Morchella.

cies cultivadas Agaricus bisporus (champiñón) y Pleurotus ostreatus (hongo ostra). Con el cultivo de especies arbóreas exóticas como Pinus radiata, se han introducido al país y por ende a la X Región, varias especies de hongos simbiontes, los carpóforos de algunos de ellos son comestibles y en los últimos años han llegado a ser un producto de exportación. Las exportaciones de carpóforos de hongos silvestres representan más de 2 millones de dólares al año y el $90 \%$ de ellas la constituyen Suillus luteus y Lactarius deliciosus. Ambas fructi- 
fican en bosques de $P$. radiata, de entre 6 y 20 años y según Peredo et al. (1983); Garrido (1981, 1983) y Valenzuela et al. (1992) la mayor productividad de carpóforos se encuentra en bosques de entre 7 y 17 años, en los meses de Otoño. Estos mismos autores han determinado que mientras más pobre es el suelo, se registra una mayor productividad de carpóforos. En Chile, además de los carpóforos de $\boldsymbol{S}$. luteus y $\mathbf{L}$. deliciosus se pueden recolectar los de otros hongos silvestres comestibles pertenecientes a Agaricales, Boletales, Russulales, Aphyllophorales, Gasteromycetes y Ascomycetes. Estos hongos fructifican sobre diversos sustratos vegetales o en el suelo de bosques, jardines, praderas, etc., y se comportan como saprófitos, parásitos o simbiontes.

Chile posee excelentes condiciones climáticas para el desarrollo de los hongos silvestres comestibles, especialmente si se consideran las amplias superficies forestales existentes y su crecimiento potencial. Pese a la situación precaria en que se trabaja este recurso natural, presenta una buena rentabilidad económica, la que podría aumentar considerablemente aplicando una adecuada administración y tecnología.

\section{MATERIAL Y METODO}

El material biológico (carpóforos) ha sido recolectado en distintos sustratos y lugares de la X Región de Chile. Las características macro - microscópicas de valor taxonómico de los carpóforos (forma, tamaño, color, olor, ascos, basidios, cistidios, esporas, etc.) se determinaron como lo indica Moreno et al., (1986). Para determinar la especie a que pertenecen los carpóforos en estudio, se compararon sus características con aquellas que aparecen en manuales y textos de taxonomía, entre otros Alessio (1985); Bigelow \& Smith (1969); Breintenbach \& Kräzlin (1991); Hesler \& Smith (1979); Horak, (1977, 1979); Singer (1969, 1986); Smiths \& Thiers (1971). El material estudiado se conserva en el herbario del Departamento de Biología Vegetal, Universidad de Alcalá (AH) España y un duplicado en el herbario particular (E. Valenzuela), Universidad Austral de Chile.

\section{RESULTADOS Y DISCUSION}

Agaricus arvensis Schäffer: Fr., Syst. Mycol. 1: 282 (1821).

Nombre común: champiñon. Píleo de 4-10 cm de diám., convexo, glabro a algo escamoso, blanco a ocráceo hacia el disco, al roce se torna amarillo. Margen entero con restos colgante de velo. Láminas libres, café-negruzco. Estípite de 7.5-12.5 x 1-2 cm, cilíndrico, base bulbosa, blanco, al roce se torna amarillo. Anillo súpero, blanco, amplio, formado por un estrato superior, una sutil membrana y uno inferior disociado a modo de rueda de carreta. Carne espesa, blanca a ocrácea en el estípite. Olor a almendras. Esporas de 6.5- 9 × 5-6 $\mu \mathrm{m}$, anchamente elipsoidales, lisas, sin poro germinativo, púrpuramarrónes. Basidios claviformes. Cistidios de 10-45 x 8$11 \mu \mathrm{m}$, subclaviformes a globosos, hialinos. Pileipellis formada por hifas cilíndricas, hialinas. Fíbulas no observadas. Especies próximas a $\boldsymbol{A}$. arvensis son $\boldsymbol{A}$. macrosporus de porte más pequeño, la carne al corte toma tonalidades rosadas, olor urinoso y esporas de 7-9 x 4-5 $\mu \mathrm{m}$; A. sylvicola que presenta anillo no en forma de rueda de carreta y esporas de medidas distintas. En Chile $\boldsymbol{A}$. arvensis se distribuye desde Viña del Mar a Valdivia. Los carpóforos se encuentra en forma solitaria a cespitosa en jardines y praderas. Fructifica entre Abril hasta mediados de Junio.

Agaricus campestris L.: Fr., Syst. Mycol. 1: 281 (1821) (s.t.) J. Lange, Dansk Botanisk Arkiv 4: 12 (1926).

Nombre común: champigñon de campo. Píleo de 4-9 cm de diám., convexo-extendido, liso, blanco o con pequeñas escamas blanco-cremosas. Láminas libres, cafénegruzco. Estípite de 3-7 x 1-2 cm, blanco, cilíndrico algo atenuado en la base. Anillo súpero, blanco, simple y fugaz. Carne espesa, blanca al corte rosado muy débil. Olor y sabor agradables. Esporas de 7-8 x 4-5.5 $\mu \mathrm{m}$, ovoides, lisas, púrpura-marrónes. Basidios claviformes. Cistidios ausentes. Pileipellis formada por hifas cilíndricas, hialinas. A. campestris suele confundirse con A. pampeanus Speg., el cual presenta esporas de 8.2-10 x 5.4-7 $\mu \mathrm{m}$, con poro germinativo evidente, también se confunde con $\boldsymbol{A}$. xanthodermus el cual se caracteriza por que sus carpóforos al roce se tornan amarillos en todas sus partes. A. campestris aparece citado en Chile desde Santiago a Magallanes. Fructifica de forma aislada a cespitosa en praderas, vegas, prados y bosques (en suelo, bajo Acer negundo, Populus nigra y P. pyramidales). Fructifica desde finales de Marzo hasta finales de Mayo.

Agaricus macrosporus (Möller \& Schäffer.) Pilát. Acta Musei Nationale Pragae VII B, 1:9 (1951).

Nombre común: champigñon de campo. Píleo de 8-20 cm de diám., convexo-extendido, blanco con la edad crémeo y con abundantes escamitas, pruinoso, se torna amarillo a ocráceo en las zonas rozadas. Margen convoluto, con restos flocosos de velo blanco. Láminas libres, marrón-púrpura a negruzco. Estípite de 5-10 x 2-4 $\mathrm{cm}$, fusiforme de base radicante, furfuráceo-pruinoso en toda su longitud, concoloro al píleo y con un anillo súpero, flocoso-furfuráceo en su cara inferior. Carne blanca tornándose en el estípite algo rosada al corte. Olor a orín 
de caballo. Sabor dulzaino. Esporas de 10-13 (15) x 6-7 $\mu \mathrm{m}$, anchamente elipsoidales, lisas, sin poro germinativo, marrones oscuras. Basidios claviformes. Cistidios de 831 x 6-16 $\mu \mathrm{m}$, subglobosos a ovoides. Pileipellis filamentosa formada por hifas cilíndricas, hialinas. Fíbulas no observadas. A.macrosporus es próximo a A.arvensis, el cual presenta un porte más pequeño, la carne al corte no se torna rosada, su olor en la madurez no es urinoso y las esporas son de 6.5-8 x 4-5 $\mu \mathrm{m}$. También suele confundirse en el campo con A.campestris y A.pampeanus. A. macrosporus sólo ha sido citado desde Valdivia, los carpóforos son muy abundante en praderas, jardines y cercanías de bosques de Pinus radiata. Fructifica desde finales de Marzo a finales de Mayo.

Amanita rubescens (Pers.: Fr.) Gray, Nat. Arr. Brit. Pl.: 600(1821) Figura 1B.

Nombre común: no tiene. Píleo de 5-15 cm de diám., convexo-extendido, marrón-blanquecino con tonalidades vinosas o rojizas en la vejez donde ha sido comida por animales, cubierto por pequeñas placas algodonosas blanquecinas que se vuelven marrones y se distribuyen en forma regular. Estípite de 5-15 cm, cilíndrico a claviforme, blanquecino a marrón-vinoso, volva ovoide-napiforme, rojo-vinosa y a menudo atacada por larvas de insectos. Anillo apical, amplio, blanco a rosado con estrías en la cara superior y borde festonado. Carne espesa, blanca que pasa a marrón-vinaceo al contacto con el aire. Esporas de 8-11 x 6-8 $\mu \mathrm{m}$, anchamente elipsoidales, lisas, hialinas, amiloides.

A. rubescens se puede confundir con A. panterina (D. C.: Fr.) Kummer (especie que no se encuentra en Chile), esta última es muy tóxica, de carne inmutable al corte, volva circuncisa y esporas no amiloides. A. rubescens se considera una buena especie comestible, pero debe consumirse bien cocida (tóxico en crudo). Se encuentra en Chile desde Concepción a Osorno. Es una especie alóctona, introducida en Chile como micorrizógeno de $P$. radiata. En forma nativa se encuentra en Europa y U.S.A. En Chile fructifica en bosques de $P$. radiata y Quercus robur. Observaciones de campo en los alrededores de Valdivia y Osorno (Popoén), permiten indicar que también fructifica en bosque de $N$. dombeyi comportándose como un micorrizógeno más o menos amplio de coníferas y caducifolios. Fructifica desde Mayo a Junio, también sus carpóforos han sido recolectados en Febrero, Agosto y Noviembre.

Armillariella mellea (Vahl.: Fr.) Karst., Acta Soc. Fauna Fl. Fenn. 2: 4 (1881).

Nombre común: No tiene. Píleo globoso a anchamente convexo de color miel con tonos marronesrosados a pardo-rojizos con pequeñas escamas fugaces abundantes hacia el centro. Láminas blanco-crémeo con máculas rojizas en la madurez. Estípite fusiforme, curvado, marrón-rojizo, ennegrece a partir de la base. Anillo apical, blanco membranoso, persistente, estriado en la cara superior. Sabor amargo a ácido. Basidios claviformes sin fíbulas en su base. Especies próximas a A. mellea son $\boldsymbol{A}$. tabescens (Scop.: Fr.) Sing., difiere por carecer de anillo, A. bulbosa (Barla) Romagn., presenta basidiocarpos cespitosos no connatos, anillo algodonoso y estípite bulboso. En Chile A. mellea se distribuye desde Aconcagua al Sur del país. Fructifica en forma saprófita, formando grandes fasciculos sobre tocones y restos leñosos de Annoma cherimola, Juglans regia, Malus pumilia, Laurelia philippiana y Nothofagus spp. En forma parásita se desarrolla en plantaciones de $P$. radiata, en árboles jóvenes y débiles. Fructifica de Mayo hasta principio de Junio.

Armillariella montagnei Sing. Lloydia 19: 182 (1956).

Nombre común: pique. Píleo de 3-5 cm de diám., campanulado a umbonado expandido, argiláceo-amarillento a castaño pálido, cubierto con diminutas escuámulas castañas. Láminas céreas, adnato-decurrentes, hialinas, volviéndose amarillentas. Estípite de 3.5-8 x 0.6-1.0 cm, cilíndrico con la base subclaviforme a subbulbosa, blanquecino, con la edad castaño, hacia la base amarillooliváceo sin rizomorfos. Anillo blanquecino, membranoso, estriado y seco. Olor ausente y sabor amargo. Esporas de 8-9.5 x 5.5-6 $\mu \mathrm{m}$, anchamente elipsoidales, hialinas, lisas. Basidios claviformes. Cistidios no observados. Pileipellis formado por hifas, hialinas. Escamas formadas por una tricodermis de hifas de 10-20 $\mu \mathrm{m}$ de diám., cortamente cilíndricas a ovoides e incrustadas con pigmento castaño-amarillento. Fíbulas presentes pero escasas. A. montagnei, es una especie común en los bosques de Nothofagus de la zona Valdiviana.

En la literatura consultada se indica que tanto $\boldsymbol{A}$. montagnei como A. montagnei var. umbrinobrunnea Sing., se encuentran en Europa. Especies próximas a $\boldsymbol{A}$. montagnei son $A$. limonea Stevenson, que presenta esporas de 6.5-8 x 5-5.5 $\mu \mathrm{m}$, píleo de hasta $10 \mathrm{~cm}$ de diám. argiláceo-ocráceo, con el disco rojizo cubierto de escuámulas castaño oscuras y estípite castaño-rojizo en la base. A. montagnei var. umbrinobrunnea Sing., difiere del tipo por su píleo umbrino-marrón, densamente escuámuloso y velo verrucoso sobre el estípite. En Chile A. montagnei se encuentra desde Valdivia a Magallanes y Argentina (Neuquén, Tierra del Fuego). Es una especie saprófita crecen sobre troncos en estado de degradación de Nothofagus dombeyi, N. pumilio, $N$. betuloides, también en Myrtaceae y Libocedrus chilensis. Se pueden recolectar entre Mayo y Junio. 
Boletus loyita Horak, Bol. Soc. Argent. Bot. 18: 104 (1977).

Nombre común: pichiloyo. Píleo de 4 (10) cm de diám., plano-convexo seco, villoso a fibriloso, rojo-vinoso a púrpura-vinoso, en la madurez marrón-vinoso-rojizo. Margen entero, concoloro al píleo. Tubos de 0.5$0.8 \mathrm{~cm}$ de largo, emarginado-subdecurrentes alrededor del estípite, ventricosos, de color amarillo profundo en la juventud, luego amarillo oro, sin tintes rojizos. Poros de hasta $0.2 \mathrm{~cm}$ de diám., poligonales, concoloros a los tubos, tornándose azules cuando se dañan o al corte. Estípite de 4-10 x 1-2 cm, subfusoide o cilíndrico, algo pruinoso, sin reticulaciones, amarillo-oro en los carpóforos muy jóvenes, en la madurez rojo-vinoso a púrpura profundo. Carne al corte amarilla en el píleo y la parte superior del estípite, tornándose azul y en la base del estípite. Sabor y olor fúngicos. Esporas de 10-11 x 3.5-4.5 $\mu \mathrm{m}$, fusiformes, lisas, amarillento a ocráceas. Basidios claviformes. Cistidios escasos de 35-50 x 9-12 $\mu \mathrm{m}$, fusoides, hialinos. Pileipellis formada por hifas cilíndricas cuyas células terminales son de mayor anchura y con pigmento plasmático e incrustante rojo-marrón en KOH 10\%. Fíbulas no observadas.

B. loyita es una especie micorrizógena endémica de los bosques de Nothofagus del Sur de Chile, presenta una estrecha relación taxonómica con $\boldsymbol{B}$. fraternus Peck, (no presente en Chile) del cual se diferencia sobre todo por sus medidas esporales. Probablemente, las escasas citas que existen en la literatura micológica chilena sobre $\boldsymbol{B}$. loyita se deben a que ha sido confundido con especies del género Xerocomus y con estadios juveniles de B. loyo. Se distribuye geográficamente sólo en Valdivia en bosques de $N$. dombeyi y $N$. obliqua. Los carpóforos se pueden recolectar desde finales de Abril hasta finales de Mayo.

Boletus loyo Phil. ex Speg., An. Mus. Nac. Hist. Nat. Buenos Aires 23: 9 (1912) Figura 1 A.

$\equiv$ Boletus loyus Espinosa, Bol. Mus. Nac. Hist. Nat. de Chile 8: (1915) .

Nombre común: loyo. Píleo de 10-35 cm de diám., convexo a plano-convexo. Cutícula seca, villosa, rojo-vinoso a púrpura, en los carpóforos maduros con tonos amarillos sobre todo cuando la cutícula se rompe en polígonos irregulares. Margen entero con un conspicuo pseudovelo membranoso. Tubos de 0.8-1.5 cm de largo, emarginadodeprimidos alrededor del estípite, amarillos y en la madurez oliva-amarillento a oliva-marrón. Poros superiores de $0.1 \mathrm{~cm}$ de diám., redondos, concoloros a los tubos o rojo-marrón. Estípite de 8-20 x 4-10 cm, robusto, claviforme a ventricoso, seco, algo flocoso o pruinoso a veces velutino, sin reticulaciones, amarillo hacia el ápice cuando joven, tornándose vinoso-rojo o púrpura en la madurez. Carne al corte consistente, amarillo-crémeo, púrpura bajo la cutícula y hacia la base del estípite. Olor y sabor a nueces frescas. Esporas de 10-15 x 4-5 $\mu \mathrm{m}$, fusiformes, lisas, amarillas en $\mathrm{KOH} 10 \%$. Basidios claviformes. Cistidios de 40-55 x 5-11 $\mu \mathrm{m}$, fusoides a cortamente rostrados con un contenido amarillento-castaño en $\mathrm{KOH} 10 \%$ o hialinos. Pileipellis formada por una cutis de hifas cilíndricas entretejidas, con pigmento plasmático e incrustante amarillo -castaño en $\mathrm{KOH} 10 \%$. Fíbulas no observadas.

B. loyo se parece a B. regius Krombholz (no presente en Chile) el cual presenta una cutícula rosa a rosapúrpura; tubos marillo-citrino con tonalidades verdosas inmutables; estípite amarillo-cromo, ornamentado con una red delicada; carne amarillo limón, rosada bajo la cutícula no vira al azul; olor y sabor desagradables. B. loyo es una especie endémica de los bosques de Nothofagus del Sur de Chile. Se distribuye sólo en los alrededores de Concepción y Valdivia. Es una especie micorrizógena de Nothofagus (N. alpina, N. dombeyi, N. glauca, N. obliqua y $N$. procera). Los carpóforos se pueden recolectar desde finales de Marzo hasta mediados de Mayo y adquirir en distintas ferias de Valdivia, La Unión y otras zonas del Sur de Chile

Bondarzewia guatecasensis (Henn.) Wright ex Sing., Sydowia 17:12 (1964).

Nombre común: bistec del pobre. Píleo flabeliformes a espatuliformes de $10-20 \times 30-50 \mathrm{~cm}$, carnoso cuando jóvenes luego coriaceo. Cutícula concéntricamente zonada, afieltrada, canela-amarillenta, con el margen lobulado a entero y más pálido. Poros poligonales de 2-3 por mm, hialinos. Estípite corto, recto, central, concoloro a la cutícula, reunidos con otros estípites en un punto radicante del cual parten numerosos píleos dispuestos en forma imbricada. Carne espesa, fibrosa. Olor fúngico. Sabor acre. Látex hialino inmutable, se secreta cuando se dañan los carpóforos. Esporas de 6.5-8 x 7-8 $\mu \mathrm{m}$, globosas, hialinas, equinadas, amiloides. Basidios cilíndricos. Cistidios ausentes. Hifas esqueléticas de 3-4 $\mu \mathrm{m}$ de diám., de paredes gruesas, hialinas. Hifas laticíferas de 3-6 $\mu \mathrm{m}$ de diám., refringentes en $\mathrm{KOH} 10 \%$, con el ápice cilíndrico. Píleipellis formada por hifas cilíndricas, hialinas. Fíbulas ausentes.

Especie caracterizada por sus basidiocarpos imbricados, coriáceos cuando secos, sistema hifal dimítico, látex hialino inmutable y esporas globosas hialinas, equinadas y amiloides. Singer (1986), incluye dentro de los Agaricales la familia Bondarzewiaceae e indica que está estrechamente relacionada con la familia Russulaceae porque sus carpóforos presentan hifas laticíferas y esporas amiloides ornamentadas, difiere de esta última familia por presentar un sistema hifal dimítico. 
Otros autores como Reijnders \& Stalpers (1992), señalan que la familia Bondarzewiaceae y por ende sus especies representan un taxon de posición incierta pues comparte características de los Aphyllophorales, como la trama himenoforal de tipo tremeloide, pero sus hifas laticíferas y sus esporas amiloides también la hacen relacionarse con Russulales, por último Pegler en Ainsworth et al. (1973), encuadra la familia Bondarzewiaceae dentro de los Aphyllophorales, señalando que el sistema hifal es monomítico y a veces aparece falsamente dimítico con hifas elongadas de paredes gruesas y algunas hifas pueden presentar fíbulas. B. guatecasensis se conoce del Sur de Chile (Valdivia) y Argentina. Es una especie considerada parásita de raíces de $N$. dombeyi, $N$. obliqua, $N$. nitida y $N$. alpina. También fructifica sobre troncos en degradación de las especies arbóreas antes señaladas. Los carpóforos se pueden recolectar en el mes de Mayo.

Coprinus comatus (Müll.: Fr.) S. F. Gray, Nat. Arr. Brit. 1: 633 (1821).

Nombre común: no tiene. Especie caracterizada por sus carpóforos de hasta $25 \mathrm{~cm}$., blanquecinos. Cutícula fibrosa que se rompe en escamas escuarrosas blanquecinas, luego presentan tonalidades marrones con el margen incurvado, liso, blanco-vinoso y delicuescente. Láminas ascendentes, blanquecinas después rosadas y finalmente negras, que delicuescen en una tinta de color negro. Estípite cilíndrico, blanco, bulboso en su base, liso a fibroso, con un anillo subapical fugaz. Sabor fúngico. Esporas de 10-14 x 6-8 $\mu \mathrm{m}$, negras, elipsoidales, lisas, con un poro germinativo apical, central y evidente. Fíbulas presentes.

Una especie próxima a $\boldsymbol{C}$. comatus es $\boldsymbol{C}$. sterquilinus (Fr.) Fr., de hábitat coprófilo, carpóforos más pequeños y esporas de $17-23 \times 10-13 \mu \mathrm{m}$. C. comatus es una buena especie comestible y sólo se deben consumir los ejemplares que posean láminas blancas o rosadas. Se distribuye en Chile desde Santiago hasta Punta Arenas. Es una especie saprófita, fructifica a orillas de caminos, jardines y especialmente en bosques con intervención antrópica, también en matorrales de Aristotelia chilensis, especie arbórea que junto a Peumus boldus, Quillaja saponaria y Lithraea caustica, forman pequeños bosques precordilleranos en la zona central de Chile. Las fructificaciones se pueden recolectar en Marzo a Mayo y Septiembre.

Cortinarius lebre Garrido, Bibl. Mycol. 120: 153 (1988).

Nombre común: hongo liebre. Píleo de 4-20 cm de diám., convexo a plano-umbonado, algo víscido, liso, finamente fibroso, vináceo en la juventud, finalmente ocre-marrón con tonos lilacinos. Margen decurvado algo ondulado o plano y roto con restos de velo submembranoso blanco. Láminas anexas a adnato-emarginadas, crema en la juventud, luego ocráceo-marrón, frecuentemente con pequeñas manchas rojo-marrón. Estípite de 615 x 1.5-3 cm, cilíndrico o atenuándose hacia la base, seco, finamente fibriloso-escuamuloso, blanquecino con tonos rojo-marrón. Velo fibriloso, blanco, formando zonas anulares sobre el estípite. Carne fibrosa, blanquecina. Olor a madriguera de liebre o como Tuber magnatum. Sabor a agarico (A. bisporus). Esporas de 8-11 x 5-7 $\mu \mathrm{m}$, anchamente elipsoidales a amigdaliformes, ocre-marrón, verrugosas. Basidios claviformes. Cistidios nulos. Pileipellis formada por hifas cilíndricas, hialinas o con pigmento no incrustante rojo-marrón, en matriz mucilaginosa. Fíbulas presentes.

Especie chilena, citada como nueva para la ciencia por Garrido (1988). Este autor indica que C. lebre, es un hongo muy apreciado y consumido por la población indígena chilena. Se conoce sólo del Sur de Chile de Concepción a Valdivia, es micorrizógeno, fructifica formando pequeños grupos en bosques de Nothofagus ( $N$. obliqua, $N$. antarctica, $N$. glauca y $N$. obliqua mezclado con Gomortega keule). Las fructificaciones se pueden recolectar entre Mayo a Junio.

Hydropus dusenii (Bres.) Sing., Beih. Nova Hedwigia 29, 1969.

Nombre común: No tiene. Píleo de 2-12 cm de diám., infundibuliforme, pardo-amarillento más pardo al centro, liso, glabro, seco. Margen incurvado, a veces lacerado, estriado, más pálido que el resto del píleo. Láminas decurrentes, blanquecino-grisáceo, a veces anastomosándose hacia la base del estípite. Estípite de 3.5-12 x 0.3-0.6 cm, blanquecino, cilíndrico igual o angostándose hacia la base, seco, fibriloso. Carne tenaz, blanquecina. Olor y sabor ausente. Esporas de 7-7.5 x 4-5 $\mu \mathrm{m}$, subglobosas a anchamente elipsoidales, lisas, hialinas, amiloides. Basidios cilíndricos, hialinos. Queilocistidios de 30-80 x 10-16 $\mu \mathrm{m}$ polimórficos (cilíndricos, claviformes o laginiformes) con el ápice a veces con proyecciones irregulares, hialinos. Pileipellis formadas por una cutis de hifas cilíndricas ramificada, hialina o con pigmento plasmático castaño en $\mathrm{KOH} \mathrm{10 \% .} \mathrm{Fíbulas} \mathrm{presentes.}$

En Chile $\boldsymbol{H}$. dusenii se distribuye en Concepción, Valdivia, Puerto natales, Magallanes, se conoce también en Argentina (Neuquén, Tierra del Fuego). Fructifica en forma gregaria a fasciculada o cespitosa sobre troncos y madera podrida o en estado de descomposición de $N$. pumilio, $N$. nitida, $N$. dombeyi, Laurelia philippiana y Cryptocarya alba. Los carpóforos se pueden recolectar entre Marzo a Mayo. 
Laccaria laccata var. pallidifolia (Peck) Peck, Ann. Rep. N. Y. St. Bot. 157: 92 (1912).

Nombre común: No tiene. Variedad que difiere del tipo por: sus basidiocarpos de colores más pálidos, medidas esporales de 6.5-13 x 6-12.5 $\mu \mathrm{m}$, por sus esporas globosas a subglobosas, raramente anchamente elipsoidales, equinuladas, hialinas. En la literatura micológica chilena, $\boldsymbol{L}$. laccata var. pallidifolia, no aparece citada, pero es probable que algunas de las recolecciones existentes y dadas como $\mathbf{L}$. laccata var. chilensis Sing., L. laccaria var. gibba Sing., y L. laccata var. laccata correspondan a la variedad pallidifolia, no existen trabajos a nivel nacional que permitan asegurar o refutar lo anterior. Se conoce desde Viña del Mar a Puerto Montt. Es un amplio micorrizógeno, fructifica en grupos en bosques autóctonos ( $N$. dombeyi y Fitzroya cupressoides) y alóctono (Quercus, Populus y P. radiata). Las carpóforos se pueden recolectar de Mayo a Julio y también en primavera.

Lactarius deliciosus (L. ex Fr.) S. F. Gray, Nat. Arr. Brit. Pls. 1: 67 (1821). Fig. 1C.

Nombre común: No tiene. Píleo de 5-20 cm de diám., plano-convexos, cóncavos cuando adultos (semeja a un embudo), cuando muy jóvenes de color verdevitriolo, luego naranja-amarillentos y en la vejez verdosos o amarillo pálidos, generalmente con zonaciones concéntricas más oscuras, glabros; contexto bien desarrollado, de color naranja, con latex de color salmón y por autooxidación verde vitroleo. Láminas subdecurrentes, subdistantes, salmones tornándose verdes al roce. Estípite de 4-11 x 1.7-3 cm, cilíndrico o atenuado o ensanchado en la base, hueco o con fosetas, glabro, escrobiculado, carnoso, seco, de color salmón, carne esponjosa blanco-salmón, con látex anaranjado-rojizo (zanahoria) al contacto del aire se torna verde-vitroleo. Sabor algo picante a veces dulce. Olor aromárico. Esporas de 8-9 x 6-7.5 $\mu \mathrm{m}$; elipsoidales a subesféricas, verrugosoreticuladas, hialinas, amiloides. Basidios cilíndricos a subclaviformes. Cistidios de 45-60 x 5-6 $\mu \mathrm{m}$, fusoidessetiformes a cilíndrico-claviformes, hialinos. Pileipellis formada por hifas cilíndricas, laticíferas y esferocistos. Fíbulas ausentes.

En Chile y dependiendo del estado de desarrollo de los carpófofos de $\boldsymbol{L}$. deliciosus, la estación del año de fructificación y el tipo de suelo, se podrían dar una gama de varidades o aproximar esta especie a $\boldsymbol{L}$. semisanguifluus Heim \& Leclair, al respecto se señala que «los cuerpos fructíferos que fructifican con las lluvias veraniegas o primeras lluvias otoñales en plantaciones de arenales presentan un estípite cilíndrico a bulboso, a diferencia de los suelos rojo que presentan un estípite nor- mal, los cuerpos fructíferos senescentes de verano usualmente son de color amarillo pálido, y los de épocas húmedas verde vitriolo». En Chile $\mathbf{L}$. deliciosus se distribuye entre Chillán a Osorno, en plantaciones de Pinus pinaster, P. radita, Pinus sp. y Pseudotsuga menziesii. Es un amplio micorrizógeno de las especies forestales antes señalada. Los carpóforos se pueden recolectar en Mayo a Junio y también en Primavera.

Lepista nuda (Bull.: Fr.) Cooke, Handb. Brit. Fungi 1: 192 (1870).

Nombre común: No tiene. Píleo de 5-15 cm de diám., convexo a plano-umbonado, no higrófano, de color violeta amatista a gris-violáceo. Margen convoluto a incurvado, no estriado y concoloro al píleo. Láminas sinuadas a subdecurrentes, violácias o amatista. Estípite de 5-10 x 1-2 cm, cilíndrico con la base claviforme a bulbosa, concoloro al píleo o pálido lila. Carne esponjosa blanco-violáceo. Sabor dulzaino. Olor y sabor afrutado. Esporas de 6-8 x 3.5-5 $\mu \mathrm{m}$, elipsoidales, verrugulosas, hialinas. Basidios claviformes. Cistidios no observados. Cutícula filamentosa con fíbulas.

L. nuda se suele confundir con $\boldsymbol{L}$. sordida (Fr.) Sing., la cual presenta un porte más pequeño y píleo higrófano. En Chile, L. nuda suele distribuirse en la zona central del país, también ha sido recolectada en Valdivia. Es una especie saprófita que fructifica en praderas, jardines, senderos de bosques de caducifolios y coníferas. Los carpóforos se pueden recolectar en Mayo a Julio.

Lepista sordida (Schum.: Fr.) Sing., Lilloa 22: 193 (1951) Figura 1E.

Nombre común: No tiene. Píleo de $3-5 \mathrm{~cm}$ de diám, plano, poco carnoso, higrófano de color lila o violeta con tonalidades marrones. Láminas sinuadas, violetas. Estípite de 3-7 x 0.5-1.5 cm, cilíndrico, blanquecino-liláceo de ápice fibriloso-pruinoso. Carne violáceoblanquecina. Olor fúngico. Sabor dulzaino. Esporas de 67 x 3-4 $\mu \mathrm{m}$, elipsoidales, verrugulosas, hialinas. Basidios claviformes. Cistidios ausentes. Cutícula filamentosa y con fíbulas. En Chile, L. sordida se distribuye en la zona Central del país y Sur. Es una especie saprófita que fructifica en praderas, prados, bordes de senderos de bosques de caducifolios y coníferas. Las carpóforos se pueden recolectar entre Mayo a Junio.

Macrolepiota procera (Scop.: Fr.) Sing., Pap. Michigan Acad. Sci. 32: 141, 1948.

Nombre común: "Parasol”. Píleo de 10-20 cm de diám., convexo-extendido, semejándose a paraguas con un fuerte mamelón obtuso en el ápice. Cutícula entera que se rompe en gruesos parches poligonales y cubierta 
de escamas y escuámulas de disposición radial, más abundantes y apretadas hacia el ápice, de color marrón sobre fondo blanquecino-rosado, el ápice mamelonado. Margen flocoso fibroso y roto. Láminas libres, blanco-níveo, anchas y apretadas. Estípite de 10-14 x 1-3 cm, cilíndrico de base bulbosa y a menudo con cordones miceliales blancos, córtex marrón uniforme que se rompe longitudinalmente en anillos zigzageantes de forma irregular y deja ver la carne blanquecina. Anillo apical, doble, móvil, blanco en la parte superior y marrón en la inferior. Carne blanca inmutable. Olor y sabor a nuez. Esporas de 14-19 x 9-13 $\mu \mathrm{m}$, lisas, con poro germinativo apical y metacromáticas en azul de cresilo. Basidios claviformes. Cistidios marginales claviformes. Cutícula filamentosa con fíbulas.

Especie fácil de reconocer por sus típicos carpóforos de grandes dimensiones en forma de «palillo de tambor» cuando muy jóvenes, o en forma de paraguas en la madurez. Especies próximas son M. fuligineosquarrosa Malençon, M. fuliginosa (Barla) Bom y M. permixta (Barla) Moser. Ningunas de ellas se encuentran citadas en Chile. $M$. procera en Chile fructifica en praderas y praderas con $N$. dombeyi y $N$. obliqua y se distribuye de Viña del Mar a Valdivia Los carpóforos se pueden recolectar desde Mayo hasta principios de Junio.

Pluteus cervinus (Schaeff.) Kummer, Führ. Pilzk. 99 (1871).

Nombre común: No tiene. Píleo de 5-12 cm de diám., campanulado, marrón con fibrillas adnatas radiales. Láminas libres, blanquecinas a rosadas en la madurez. Estípite de 5-10 x 0.5-1.5 cm, cilíndrico blanquecino con fibrillas oscuras. Carne blanquecina. Sabor y olor rafanoides. Esporas de 7-9 x 5-6 $\mu \mathrm{m}$, ovoides a elipsoidales, lisas, hialinas. Basidios claviformes. Queilocistidios claviformes, hialinos. Pleurocistidios lageniformes con digitaciones o espinas cónicas en el ápice, de paredes gruesas. Cutícula filamentosa sin fíbulas a nivel de los septos de las hifas.

Especie próxima a $\boldsymbol{P}$. cervinus es $\boldsymbol{P}$. atromarginatus (Sing.) Kühner (= P. tricuspidatus Velen, no presente en Chile), el cual presenta la arista de las láminas marrón; estípite negruzco, longitudinalmente fibriloso; esporas de 6-7.5 x 4.5-5.5 $\mu \mathrm{m}$ y se desarrolla en madera de coníferas muertas. P. cervinus se confunde frecuentemente con $\boldsymbol{P}$. curtissi (Bk. \& Br.) Sacc. ss. Sing., ss. Moser 1983 [ $=$ P. petasatus (Fr.) Gillet, no presente en Chile], cuyo píleo al menos hacia el disco es marrón a negro-marrón, fibriloso-escuamuloso o fibriloso-escamoso; estípite blanco, fibriloso-escuamuloso la base a veces marrón; esporas de 5-6.5 x 4-5 $\mu \mathrm{m}$, y fructifica sobre madera y troncos de haya. $\boldsymbol{P}$. cervinus en Chile se distribuye desde Valparaiso a Puerto Natales. Es una especie saprófita que crece en troncos podridos de
Cryptocarya alba, madera de $N$. antarctica y en suelo con materia orgánica. Los carpóforos se pueden recolectar de Mayo a Junio.

Pluteus xylophilus (Speg.) Sing., Lilloa 23: 203 (1950).

Nombre común: No tiene. Pileo de 5-9 cm de diám., convexo a plano-subumbonado, gris, hacia el centro pardo-negruzco a marrón oscuro, glabro, excepto el centro con pequeñas escuámulas marrónes oscuras y en la madurez glabro. Margen decurvado a plano, concoloro al píleo. Láminas libres, blanquecino sucio en la juventud, luego rosadas, con la arista concolora. Estípite de 48 x 0.5-1.5 cm, cilíndrico la base truncada o bulbosa, blanco, sulcado, glabro a veces hacia el tercio inferior con fibrillas adpresas pardo-marrón pálido y la base fibrilosa y grisácea. Carne espesa, blanca. Olor fúngico. Sabor fúngico. Esporas de 5.5-8 x 4-5.5 $\mu \mathrm{m}$, ovoides-elipsoidales lisas, hialinas. Basidios ventricosos. Queilocistidios dimórficos, cilíndrico-claviformes de 50-80 x 7-10 $\mu \mathrm{m}$, y vesiculosos cortos de 15-25 x 11-13 $\mu \mathrm{m}$, hialinos. Pleurocistidios de dos tipos, (1) lageniformes de 60-80 x 12-15 $\mu \mathrm{m}$, de ápice redondeado con 3 proyecciones digitiformes a modo de corona y paredes de $2-3 \mu \mathrm{m}$ de diám. (2) lanceolados de 55-80 x 11-16 x 2-4 $\mu \mathrm{m}$, de ápice agudo, paredes de 2-2.5 $\mu \mathrm{m}$. Píleipellis formada por hifas cilíndricas hialinas o con pigmento intracelular marrón. Fíbulas ausentes.

P. xylophilus se caracteriza por su estípite glabro, blanquecino, sus queilocistidios dimórficos y pleurocistidios de 2 tipos. Singer (1986) mantiene dos variedades de esta especie $\boldsymbol{P}$. xylophilus var. tucumanensis Sing., la cual presenta formas pequeña y predominio de queilocistidios veciculoso-claviformes, la otra variedad $\boldsymbol{P}$. xylophilus var. major presenta carpoforos mayores, la mayoría de los queilocistidios son cilíndrico-claviforme elongados y el píleo mayormente es blanco, excepto el disco. De acuerdo a Singer una especie próxima a $\boldsymbol{P}$. xylophilus es $\boldsymbol{P}$. harrisii Murr. (no presente en Chile), presenta cistidios dimórficos con el ápice ampliamente redondeado sin digitaciones; píleo marrón oscuro uniforme, estípite blanco sin fibrillas oscuras; esporas de 6-9.8 x 5-6.5 $\mu \mathrm{m}$, es una especie tropical del Sur de Florida a Trinidad. $\quad \boldsymbol{P}$. xylophilus se puede confundir con $\boldsymbol{P}$. cervinus (Schäeff.: Fr.) Kummer, pero este último no presenta pleurocistidios dimórficos. Singer (1986) indica que $\boldsymbol{P}$. xylophilus se distribuye desde el centro de Argentina al Amazona, es saprófito, en Valdivia fructifica en jardines con mezcla de tierra y paja de trigo, en otras latitudes fructifica sobre madera manufacturada, troncos caídos y tocones de dicotiledóneas (Schinopsis, Jacorande y Salix). Las fructificaciones han sido recolectadas por el suscrito en Noviembre y Febrero. 
Stropharia semiglobata (Batsch: Fr.) Quélet, Champ. Jura Vosg. 1: 143 (1872).

Nombre común: No tiene. Píleo campanuladoconvexo, viscoso, amarillento a ocráceo. Láminas adnatas, gris-violáceas con la arista blanquecina en la madurez. Estípite viscoso, blanco-amarillento, con restos de anillo viscoso en la parte apical que en la madurez presenta tintes violáceos por el depósito de esporas, a veces el anillo falta. Esporas elipsoidales, lisas, con un poro germinativo apical evidente; queilocistidios lageniformes y crisocistidios muy notorios. S. semiglobata puede confundirse con Psilocybe merdaria (Fr.) Ricken, pero este carece de crisocistidios y presenta esporas hexagonales, también se confunde con Agrocybe pediades (Fr.: Fr.) Fray. En Chile, S. semi-globata se distribuye desde la zona central del país a Puerto Natales. Es una especie coprófila y subcoprófila (en lugares abonados con estiércol) del ganado herbívoro (vacuno y equino). Los carpóforos han sido recolectadas en Abril - Junio y Noviembre. 259 (1945).

Suillus grevillei (Klotzch) Sing., Farlowia 2:

Nombre común: No tiene. Píleo de 5-15 cm de diám, anchamente umbonado o convexo-extendido. viscoso, glabro, amarillo-anaranjado o marrón-amarillo-anaranjado, el centro marrón-ocráceo. Margen incurvado a plano-decurvado concoloro al píleo. Tubos de 1-1.5 cm, adnatos, subdecurrentes, amarillo-citrino a amarillooliváceo. Poros poco angulosos de 1-2 por mm. concoloros con los tubos, marrones al roce o al corte. Estípite de 4-10 x 1-3 cm, cilíndrico de color amarillo-oro y con rugosidades marrón-anaranjado, hacia la base verde azufre. Anillo apical, viscoso, cortiniforme, flocoso, blanco-amarillento, que delimita el estípite en dos porciones, la superior reticulada y la inferior fibrilosa. Carne al corte amarillenta, después rosado-grisácea y débilmente verdosa en la base del estípite. Sabor y olor afrutado. Esporas de 8-11 x 3.5-4.5 $\mu \mathrm{m}$, cilíndrico-elipsoidales, lisas, amarillentas a ocráceo en $\mathrm{KOH} 10 \%$. Basidios claviformes. Cistidios de 30-60 x 6-8 $\mu \mathrm{m}$, subcilíndricos a claviformes, algunos lageniformes, hialinos con material incrustante en la base, contenido ocráceo a amarillento en $\mathrm{KOH} \mathrm{10 \% .} \mathrm{Caulocistidios} \mathrm{solitarios} \mathrm{o} \mathrm{esparci-}$ dos en pequeños fascículos. Pileipellis filamentosa, formada por hifas cilíndricas rodeadas por una matriz gelatinosa, hialinas o con contenido amarillento-ocráceo pálido. Fíbulas ausentes.S. grevillei se conoce principalmente de Europa y Norte América. En Chile, sólo se conoce de Valdivia. Es ectomicorrízico con especies género Larix, en Chile se encuentra asociada a Larix decidua. Se considera un buen comestible, teniendo la precaución de quitar la cutícula del píleo. Los carpóforos han sido recolectadas en Abril y finales de Noviembre.
Suillus luteus (L.: Fr.) Gray, Nat. Arrang. Brit. 1: 646 (1821).

Nombre común: pichi loyo. Pileo de 4-12 cm de diám., campanulado a anchamente umbonado, viscoso, amarillo-marrón a marrón-rojizo, cubierto por un mucus de tonalidad violácea y con fibras radiales que lo recorren en toda su superficie. Margen incurvado a decurvadoplano. Tubos adnatos, blanco-amarillo-limón a amarillooro. Poros pequeños, angulosos y concoloros a los tubos. Estípite cilíndrico de 3-11 x 1-3 cm, blanco a algo amarillo. Anillo apical, membranoso, blanquecino seco en la parte superior, violáceo y viscoso en la parte inferior y en tiempo seco queda unido al margen, el estípite presenta finos gránulos, dispersos, resinoides, marrónrojizos, situados entre el anillo y las inmediaciones de los tubos. Carne blanquecina, pero amarillo pálida bajo la cutícula y tubos. Olor y sabor agradables. Esporas fusiformes-elipsoidales de 7-11 x 3-3.5 $\mu \mathrm{m}$, lisas, amarillentas. Basidios claviformes. Cistidios claviformes. Cutícula filamentosa sin fíbulas y gelificada. Especie ectomicorrízica de coníferas (Pinus pinaster, P. radiata, $P$. silvestris y Pseudotsuga menziesii) que fue introducida en Chile con el $P$. radiata. Se considera muy buen comestible, pero es necesario quitar la cutícula y tubos si están demasiado blandos. En Chile se distribuye desde Viña del Mar a Osorno. Los carpóforos han sido recolectados Marzo - Junio y Septiembre - Noviembre.

Suillus tomentosus (Kauffman) Sing., Snell, \& Dick, Mycologia 51: 570 (1960).

Nombre común: No tiene. Píleo de 4.4-10.2 cm de diám., convexo a anchamente convexo, amarillo pálido o anaranjado-amarillo pálido más oscuro en la madurez, tomentoso-flocoso, con escamas a escuámulas parduscas. Margen algo incurvado y con un tomento muy tosco. Poros pequeños marrones a vináceo-marrón o amarillo-marrón. Tubos de 1-2 cm de longitud, adnados a decurrentes, amarillo pálido, en la madurez verde-amarillo sucio, se tiñen azul-verdoso al rozarlos o en los ejemplares envejecidos. Estípite de 3.3-10 x 1-2 cm, cilíndrico a claviforme, concoloro con el píleo, todo cubierto de gránulos, sin restos del velo universal. Carne amarillo sucio volviéndose azul a azul-verdoso al corte. Sabor algo ácido, olor fúngico. Esporas de 9.5-12 x 3.5-4 $\mu \mathrm{m}$, fusiforme-elipsoidales, lisas, amarillo pálido. Basidios claviformes. Pleurocistidios de 37-42 x 7-9 $\mu \mathrm{m}$, subcilíndricos a claviformes de ápice obtuso, hialinos, amarillentos en $\mathrm{KOH} 10 \%$. Queilocistidios y caulocistidos similares a los pleurocistidios, frecuentemente con pigmento amorfo marrón. Pileipellis en las escuámulas formada por un trichodermis de hifas fusiformes y cilíndricas, la mayoría con un contenido marrón. Fíbulas no observadas. S. tomentosus se puede confundir con S. fusco- 
tomentosus Smith \& Thiers (no citado en Chile), pero en esta especie la carne no vira al azul. Una especie europea próxima es $\boldsymbol{S}$. variegatus (no citado en Chile) el cual se diferencia por su píleo afieltrado en la juventud, luego cubierto de finas escuámulas, estípite no granuloso y su carne azulea débilmente. Además fructifica con Pinus silvestris y P. mugo en suelos ácidos y arenosos. En Chile $\boldsymbol{S}$. tomentosus sólo ha sido recolectado en Valdivia. Esta especie es común en la parte Oeste de los Estados Unidos desde finales del verano y principios del invierno, se encuentra de forma dispersa a gregaria bajo Pinus spp. y otras coníferas. También es común en California, fructifica bajo Pinus de 2 y 3 acículas, entre Septiembre a Octubre. Arora (1986), señala que fructifica en California con $P$. contorta y en bosques mixtos de Pinus y Populus. En Valdivia, S. tomentosus se comporta como especie ectomicorrízica de Pinus sp. y Abies sp. y los carpóforos han sido recolectadas en Mayo.

Xerocomus chrysenteron (Bull.) Quélet, Fl. Mycol. Fr. 448(1888).

Nombre común: No tiene. Píleo de 4-8 cm de diám., convexo-extendido, velutino a pubescente, de color marrón variable, marrón rosado con tonos marrónoliváceos, seco, agrietado y roto a modo de las piezas de un rompecabezas que dejan ver la carne subcuticular de color rojo-sangre. Margen plano-decurvado. Tubos adnatos a adnatos-subdecurrentes amarillos a amarilloverdosos. Poros angulosos, concoloros con los tubos, que toman tonos azulosos al rozamiento. Estípite cilíndrico, de 3-7 x 0.6-1.5 cm, salpicado de pequeños gránulos de color rojizo-carmín. Carne blanquecina-amarillenta, rojopúrpura bajo la cutícula, que vira a azul al corte o rozamiento, olor no apreciable, sabor dulzaino. Esporas elipsoidales-fusiformes de 10-15 x 4-7 $\mu \mathrm{m}$, ocráceas, lisas. Basidios claviformes, cistidios fusiformes, suprapellis o epicutis en tricodermis, con pigmento parietal, la última célula del filamento cilíndrica y de ápice obtuso. Fíbulas no observadas.

$\boldsymbol{X}$. chrysenteron, se puede confundir con $\boldsymbol{X}$. truncatus Sing., Snell \& Dick (no presente en Chile), que sólo puede diferenciarse por poseer poro germinativo en el ápice de la espora y carecer de carne subcuticular de coloración rojiza. A nivel mundial $\boldsymbol{X}$. chrysenteron se distribuye por todo el hemisferio boreal o septentrional y es conocida también en América del Sur. Fructifica en bosques de coníferas y caducifolios, en suelos ricos en humus e incluso sobre restos de madera descompuesta. En Chile se localiza entre Concepción a Valdivia. Es ectomicorrízica de P. radiata, Eucalyptus spp. y Salix spp. También se comporta como saprófito alrededor de tocones de Populus. En la Octava Región de Chile $\boldsymbol{X}$. chrysenteron es recolectado en viveros forestales de $P$. radiata, prefiere para su desarrollo suelos arenosos, con alta humedad (hasta 33\%) y pH 5.35-5.40, siendo dominante junto con Rhizopogon roseolus entre Abril y Mayo, luego de la declinación de Scleroderma citrinum. En Valdivia, los carpóforos han sido recolectados desde finales de Abril a principio de Junio y a veces en Noviembre.

Fistulina hepatica Schaef.: Fr. var antarctica (Speg.) Wright, Rev. Invest. Agrop. INTA, ser. 5, Pat. Veg. 9: 130, 1972. Figura 1D.

Nombre común: lengua de buey. Cuerpo fructífero anual, espatulado a dimidiado o en forma de lengua, de hasta $15 \mathrm{~cm}$ de largo por $10 \mathrm{~cm}$ de ancho y 0,5-2.5 cm de grosor, sésiles o con un estípite lateral corto. Píleo demediado-flaveliforme o a modo de lengua, liso a veces con algunas escámulas y/u ondulaciones; cuando joven castaño ceniciento claro, haciéndose más castaños y rojizos con la edad, de aspecto sanguinolento y húmedo, submucoso cuando fresco. Margen redondeado, a veces recurvado hacia arriba. Contexto concoloro, muy gelatinoso, aunque tenaz, cuando viejo subesponjoso. Himenóforo tubular, con tubos libres entre si, de desigual longitud y edad en algunos ejemplares. Tubos de hasta $1 \mathrm{~cm}$ de largo, frágiles en los ejemplares secos con poros de color castaño-rojizo, sabor algo salado. Esporas de 4.6-5 x 3.6-4.7 $\mu \mathrm{m}$, ovoides a anchamente elipsoidales, hialinas a algo amarillentas, lisas de paredes gruesas. Basidios claviformes. Sistema hifal monomítico, con la superficie del píleo formada por los extremos redondeados en forma de clava alargada de las hifas superiores del contexto, a modo de pelos, rojos feluginosos con fíbulas en la base de 145-232 x 11,5-22 $\mu \mathrm{m}$; las del contexto distribuidas en una capa gelatinosa angosta de hifas muy entrelazadas con fíbulas y una capa esponjosa con hifas muy entrelazadas de 4.8-9.5 $\mu \mathrm{m}$ de diám., pero con células ensanchadas en la parte media; en este estrato se observan hifas conductoras de mayor tamaño, contienen un jugo castaño-rojizo. Hacia el exterior de los tubos se diferencian largos «pelos» hifales, que se van incurvando en dirección opuesta a la luz del tubo, algunos con paredes corrugadas y con incrustaciones de material cristalino. En Chile $\boldsymbol{F}$. hepatica var antarctica se localiza entre Temuco al Sur. Bosques andinopatagónicos de la Argentina y Chile. Especie que al parecer parásita Nothofagus, especielmente $N$. antarctica (posiblemente produce una pudrición castaña). Se consumen los ejemplares jóvenes, cocidos o crudos una vez troceados a modo de rebanadas en ensaladas. Los carpóforos han sido recolectadas desde Enero hasta finales de Marzo. 1969.
Grifola gargal Sing., Mycoflora Australis 381, 

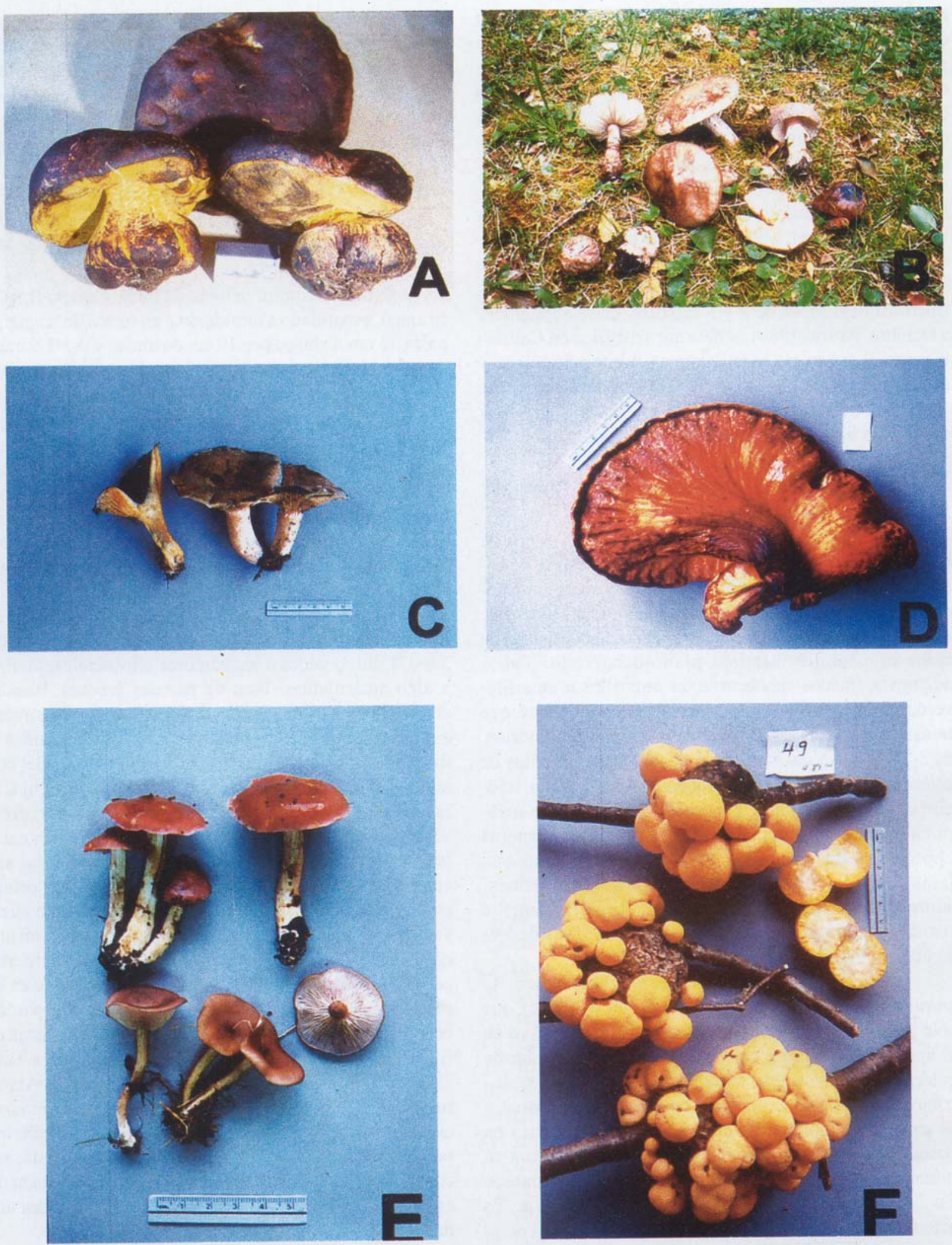

Figura 1.- Cuerpos fructíferos de: $\mathbf{A}=$ Boletus loyo $\mathbf{B}=$ Amanita rubescens. $\mathbf{C}=$ Lactarius deliciosus $\mathbf{D}=$ Fistulina hepatica var. antarctica $\mathbf{E}=$ Lepista sordida $\mathrm{F}=$ Cyttaria hariotii. 
Nombre común: gargal. Cuerpo fructífero en forma de ramillete, multipileado, subdividido en numerosas ramas, carnosos cuando frescos y jóvenes. Píleo flabeliformes a espatuliformes, carnoso en la juventud luego coriáceo. Cutícula afieltrada, café-canela oscuro a suboliváceo oscuro, con el margen lobulado a entero, algo estriado y más pálido. Poros blancos, lacerados. Estípite corto, recto, central, concoloro a la cutícula, reunidos con otros estípites en un punto radicante del cual parten numerosos píleos dispuestos en forma imbricada. Carne espesa blanca, olor fúngico, sabor astringente a subamargo. Esporas de 7-7.5 x 5.2-5.5 $\mu \mathrm{m}$, elipsoidales, hialinas, no amiloides; de pared subténue y heterogenea, aparentemente lisas pero con espinas inmersas. Basidios claviformes, hialinos, cistidios ausentes, píleipellis formada por una trama de hifas cilíndricas, tabicadas no amiloides, hialinas en una matriz mucilaginosa. Fíbulas presentes. Especie caracterizada por sus basidiocarpos imbricados. G. gargal difiere de $\boldsymbol{G}$. frondosa por las medidas esporales y las paredes de las esporas son muy heterogéneas. En la zona valdiviana los basidiocarpos de $\boldsymbol{G}$. gargal se consumen en forma cocida, ya que semejan al cuajar o librillo del estómago de los vacunos, llamados popularmente «guatitas». En Chile se localiza entre Temuco y Valdivia. También en los bosques andinopatagónicos de la Argentina y Chile. Especie que se encuentra al pie de Nothofagus spp., y en troncos de estas especies arbóreas. Las fructificaciones han sido recolectadas entre Mayo y Junio. 1888

Ramaria flava (Fr.) Quél., Fl. Mycol. 466,

Nombre común: Changles. El género Ramaria se encuentra representado en la zona Sur de Chile por aproximadamente 6 especies y 4 variedades, algunas son Ramaria flava (Fr.) Quél., var. subtilis (Coker) Corner; $\boldsymbol{R}$. flava (Fr.) Quél., var. parvispora (Coker) Corner y $\boldsymbol{R}$. valdiviana Sing. La taxonomía de éste género sus especies y variedades en Chile no se han establecido con claridad y necesita ser revisada. Tanto las especies y variedades se diferencian por el color de los carpóforos, por el tamaño y ornamentación de las esporas, presencia o ausencia de fíbulas y otros caracteres. En la zona de Valdivia estos hongos y especialmente $\boldsymbol{R}$. flava var.. subtilis es la más común de las especies comestibles y se comercializa bajo el nombre de «changle».

En Chile se localiza entre Viña del Mar y Puerto Montt. También en los bosques andinopatagónicos de la Argentina y Chile. Las especies de Ramaria son micorrizógenas, fructifican en el suelo al pie de Nothofagus spp. y Austrocedrus chilensis, también se encuentra en el suelo en matorrales de Chusquea quila con Nothofagus spp. Los carpóforos han sido recolecta- das entre los meses de Marzo a Mayo y a veces en Septiembre.

Scleroderma citrinum Pers., Syn. Meth. Fung. 153, 1801. sensu Garrido 1981.

Nombre común: No tiene. Carpóforos aislados a cespitosos de 2-4 ejemplares unidos, globosos de 3-6 $\mathrm{cm}$ de diám, escamoso a subliso, con pequeñas grietas apicales o surcos longitudinales. El grosor del peridio es de $1 \mathrm{~mm}$ aproximadamente, duro, coriáceo, crema-amarillento, con escamas rojizas. Dehiscencia en la madurez irregular por las grietas apicales. Pseudoestípite formado por restos de micelio blanco. Gleba pulverulenta variando de color blanquecino a verdoso, marrón-negruzco finalmente negra. Esporas globosas, marrones de 11-12 $\mu \mathrm{m}$ (sin la ornamentación), ornamentación de 2-3 $\mu \mathrm{m}$, reticuladas y espinosas. Basidios cilíndricos-claviformes. Hifas de la gleba, marrones, tabicadas y fibuladas. $\boldsymbol{S}$. citrinum es una especie abundante en plantaciones de $P$. radiata, forma asociación ectomicorrícica. Garrido (1981), señala que es muy abundante en suelos arenosos y escasa en suelos rojos teniendo los carpóforos menor tamaño en este último suelo. Su uso culinario es discutido se indica que esta especie es consumida en Checoslovaquia sustituyendo las trufas, otros señalan que es tóxica. En Chile se distribuye entre Concepción a Magallanes. Fructifica desde finales de Abril a Junio y a veces en Septiembre.

De los Ascomycetes silvestres comestibles sólo se indican algunos datos, pues taxonómicamente no han sido analizados por el autor del presente trabajo, pero se han recolectados en la zona de Valdivia.

\section{Gyromytra cf. esculenta}

Nombre común: Chicharón de campo. Píleo de 2$5 \mathrm{~cm}$ de diám., castaño rojizo, cuando muy viejo negro, convoluto a cerebroide, margen inflexo. Estípite de 2-6 cm de altura, blanquizco a rosado-grisáceo, hueco. Carne espesa blanca. Olor y sabor fúngico. Ascos cilíndricos, octosporados de ápice amiloide. Ascosporas elipsoidales, gutuladas, hialinas, lisas. Paráfisis filiformes, tabicadas y con el ápice claviforme. Esta especie se consume a nivel local (Valdivia), la literatura consultada señala que $\boldsymbol{G}$. esculenta es considerada una especie tóxica en Europa razón por la que se ha prohibido se venta en algunos países.

En Chile las especies de Gyromytra se distribuye entre Viña del Mar a Punta Arenas. Gyromytra cf. esculenta fructifican en grupos cespitosos sobre suelo quemado y G. antarctica Rehm, crece sobre madera. Los carpóforos de $\boldsymbol{G}$. cf. esculenta son recolectadas durante Mayo hasta mediados de Junio. 


\section{Morchella St. Amans.}

Nombre común: No tiene. Las morchellas que han citado para Chile podrían corresponden $\boldsymbol{M}$. conica y $\boldsymbol{M}$. esculenta. Los carpóforos llegan a medir hasta $15 \mathrm{~cm}$ de altura, el píleo es subgloboso o cónico de ápice obtuso, cuya superficie himenial semeja a un panal de abejas; el estípite es cilíndrico de base claviforme blanco y hueco. Ascos cilíndricos y no amiloides y octosporados. Ascosporas elipsoidales, lisas y hialinas. Olor y sabor fúngico. En Chile las especies de Morchella se distribuyen entre Santiago y Osorno. En la zona valdiviana fructifican en grupos o en forma cespitosa en bosques de coníferas y caducifolios, más raramente en praderas, durante Abril hasta mediados de Junio.

Cyttaria hariotii Berkeley. Fig.1 F.

Nombre común: dihueñe, pinatras, caracucha y llaullau. Ascoestromas de 1-5 cm de diám., globosos (en forma de pelota de golf) o turbinados, carnosos anaranjados. Apotecios situados en la periferia de estas fructificaciones, cuando muy jóvenes cubiertos por una membrana blanca. Ascos cilíndricos, no operculados, octosporados. Ascosporas subglobosas. Paráfisis filiformes, ramificadas o simples. Especies parásitas débiles de ramas de diversos Nothofagus, causan agallas. El género Cyttaria ha coevolucianado en forma específica con las distintas especies de Nothofagus, que se distribuyen por Australasia. En Chile las especies de Cyttaria se distribuyen de preferencia entre la IX y X Región. Fructifican en grupos sobre ramas de diversas especies de Nothofagus durante Septiembre y Octubre.

Lista de Basidiomycota (Agaricales y Boletales) silvestres comestibles que fructifican en otras Regiones de Chile o son escasos en la Provincia de Valdivia.

Agaricus augustus Fr., Epicr. Syst. Mycol. 212, 1836.

Nombre común: no tiene. Distribución: Colchagua. Hábitat: sobre humus. Temporada: Junio.

Agaricus arvensis Schff. ex Fr. Syst. Mycol. 1: 281, 1821.

Nombre común: no tiene. Distribución: Viña del Mar a Concepción. Hábitat: en pradera. Temporada: Otoño.

Agaricus bisporus (Lange) Imbach, Mitt. Naturf. Ges. Luzern 15: 15, 1946.

Nombre común: champignon. Distribución: Santiago (Maipú y Melipilla) y Concepción. Hábitat: sobre humus. Temporada: finales de Otoño y principio de Primavera.
Agaricus porphyrizon Orto, Trans. Brit. Mycol. Soc. 43: 174, 1960.

Nombre común: no tiene. Distribución: Viña del Mar. Hábitat: sobre suelo. Temporada: Otoño.

Agaricus xantholepis (Moell.) Moell., Friesiana 4: 204, 1952.

Nombre común: no tiene. Distribución: Valdivia (Hueycolla). Hábitat: en humus. Temporada: Otoño (Mayo).

Agrocybe aegerita (Brig.) Singer, Schweiz. Z. Pilzk. 17: 21, 1939.

Nombre común: no tiene. Distribución: Chile central y austral. Hábitat: en sauces o álamos vivos o muertos. Temporada: Otoño (mayo) e Invierno.

Agrocybe cylindrica (Fr.) Maire, Mem. Soc. Sci. Nat. Maroc. 45: 106, 1938.

Nombre común: no tiene. Distribución: Santiago; Rancagua; Valdivia. Hábitat: sobre árboles vivos o muertos o troncos recién cortados de Salix spp. En maderos podridos de Populus pyramidalis y P. canadensis. Temporada: Otoño (mayo).

Camarophyllus niveus (Fr.) Wünsche, Die Pilze 115. 1877.

Nombre común: no tiene. Distribución: Chile central (La Viñita, Pumanque) y austral. Hábitat: en suelo de bosques deciduos y de coníferas. Temporada: Julio.

Clitocybe espinosae Singer, Beih. Nova Hedwigia 29: 33, 1969.

Nombre común: no tiene. Distribución: Santiago; Linderos. Hábitat: sobre suelo con árboles subxerofiticos. Temporada: Febrero.

Clitocybe fragrans (Sow.: Fr.) Kummer, Führer Pilzk. 121, 1871.

Nombre común: no tiene. Distribución: Concepción (Loma Colorada). Hábitat: en suelo con Pinus radiata, sobre todo en bosques alterados. Temporada: desde finales de Abril a principios de Julio.

Clitopilus prunulus (scop.: Fr.) Kummer, Führer Pilzk. 97, 1871.

Nombre común: no tiene. Distribución: Valparaíso (Los perales) Hábitat: en suelo, bajo Beilschmiedia miersii. Temporada: Otoño (Mayo).

Collybia butyracea (Bull.: Fr.) Kummer, Führer Pilzk. 117, 1871. 
Nombre común: no tiene. Distribución: Viña del mar y Concepción. Hábitat: en suelo en hojas de Nothofagus pumilio y $N$. betuloides, también en bosques de $P$. radiata. Temporada: Abril a finales de Junio.

Flammulina velutipes (Curt.: Fr.) Singer, Lilloa 22: 307, 1951.

Nombre común: no tiene. Distribución: Chile central y austral. Hábitat: en madera muerta y tocones de arboles. Temporada: Otoño (Marzo).

Hygrocybe coccinea (Schff.: Fr.) Kummer, Führer Pilzk. 112, 1871.

Nombre común: no tiene. Distribución: Viña del Mar; Colchagua (Pumanque). Hábitat: sobre suelo. Temporada: Finales de Agosto a Septiembre.

Lepista personata (Fr.) Cooke, Handb. Brit. Fungi 1: 193, 1870.

Nombre común: no tiene. Distribución: Santiago (Quinta Normal), Talagante, Maipú. Hábitat: sobre cespedes y suelo con hojarascas. Temporada: desde Mayo a finales de Agosto.

Leucoagaricus naucinus (Fr.) Singer, Lilloa 22: 418, 1951.

Nombre común: no tiene. Distribución: Santiago. Hábitat: en praderas. Temporada: Marzo a principios de Mayo.

Macrolepiota bonaerensis (Speg.) Singer, Lilloa 22: 417, 1951.

Nombre común: parasol. Distribución: Concepción. Hábitat: en plantaciones de P. radiata y Eucalyptus globulus. Temporada: finales de Abril hasta finales de Mayo.

Macrolepiota rhacodes (Vitt.) Singer, Lilloa 22: 417, 1951.

Nombre común: parasol. Distribución: Viña del Mar. Hábitat: en suelo con humus. Temporada: Mayo a principios de Junio.

Phaeogyroporus beniensis Singer \& Dig., Lilloa 30: 150, 1960.

Nombre común: no tiene. Distribución: Concepción. Hábitat: Sobre suelo, tocones y troncos podridos de P. radiata. Temporada: Marzo a Abril.

Pleurotus ostreatus (Jacq.: Fr.) Quélet, Champ. Jura Vosg.. 1: 112, 1872.

Nombre común: hongo ostra. Distribución: Chile central y austral. Hábitat: sobre troncos y ramas de diferentes especies arbóreas. Temporada: Otoño (Mayo).
Pluteus spegazzinianus Singer, Sydowia 6: 221, 1952.

Nombre común: no tiene. Distribución: Colchagua y Magallanes. Hábitat: sobre troncos y restos de madera podrida de Nothofagus pumilio y N. betuloides. Temporada: Marzo a Junio.

Suillus granulatus (L.: Fr.) Kuntze, Rev. Gen. Pl. 3: 535, 1898.

Nombre común: no tiene. Distribución: Viña del Mar; Santiago. Hábitat: en suelo, ectomicorrizogeno con P. radiata. Temporada: Mayo a Junio.

Volvariella speciosa (Fr.: Fr.) Singer, Lilloa 22: 401, 1951.

Nombre común: no tiene. Distribución: Santiago; Rancagua y Talca. Hábitat: en praderas con humus. Temporada: Mayo a finales de Julio.

\section{CONCLUSIONES}

En Chile se encontrarían aproximadamente 53 especies de hongos silvestres comestibles (autóctonos y alóctonos), que pertenecen a la División Basidiomycota o Ascomycota. Estos hongos se comportan como saprófitos, parásitos o simbiontes (micorrizógenos), fructifican sobre diversos sustratos vegetales o en el suelo de bosques (autóctonos y alóctonos), praderas, jardines, etc.

En la zona de Valdivia es posible recolectar 30 especies distintas de hongos silvestres comestibles. Destacando entre los apetecidos por la población local: Agaricus campestris (champigñon de campo), $\boldsymbol{A}$. macrosporus (champiñon), Armillariella montagnei (pique), Boletus loyo (loyo), Grifola gargal (gargal), Ramaria flava var. subtilis (changle), Gyromytra cf. esculenta (chicharón de campo) y varias especies de Cyttaria (dihueñe, pinatra, llaullau).

De las especies de hongos silvestres presentes en Chile, por su excelente sapidez y demanda en el mercado internacional, cabe destacar los siguientes: Agaricus arvensis, Lactarius deliciosus, Macrolepiota bonaerense, Suillus luteus, Volvariella especiosa, Xerocomus chrysenteron y varias especies de Morchella.

Más del 90\% de las exportaciones de hongos que realiza Chile, están constituidas por las especies $\boldsymbol{S}$. luteus y $\mathbf{L}$. deliciosus.

Para mejorar el volumen y la diversidad de las exportaciones de hongos que realiza el país, es aconsejable, realizar una profunda investigación sobre la posibili- 
dad de obtener en cultivos varias especies de los hongos silvestres nativos. Esto podría abrir otros mercados, fuentes de trabajo y la creación de agroindustrias.

\section{AGRADECIMIENTOS}

A los proyectos DID-UACH 200210 y FONDEF D02I-1003 por financiar parte de este estudio. Al Dr. E. Horak por su ayuda y material bibliográfico enviado.

\section{REFERENCIAS}

Ainsworth, G.; Sparrow, F. \& Sussman, A. (1973). The Fungi. An Advanced Treatise. Academic Press, New York and London. Vol. IV

Alessio, C. (1985). Boletus Dull. ex L. 2. Fungi Europaei. Libreria editrice Giovanna Biella. Saronno.

Arora, D. (1986). Mushrooms demystified a comprehensive guida to the fleshy fungi. Ed. Soronno. Speed Press. Berkeley.

Bigelow, H. \& Smith, A. (1969). The status of Lepista a new section of Clitocybe. Brittonia 21: 144-177

Breintenbach, J. \& Kräzlin, E. (1991). Champignons de Suisse, contribution á la connaissance de la flore fongique de Siusse. Ed. Mykologia Lucerne.

Garrido, N. (1981). Contribución al conocimiento de los Agaricales (Mycota-Basidiomycetes) en plantaciones de Pinus radiata D. Don en la Octava Región de Chile. Tesis Dept. Botánica, Universidad de Concepción, Chile.

Garrido, N. (1983). Las Bolataceae en plantaciones de Pinus radita D. Don en Chile. Bol. Soc. Biol. Concepción, Chile 54: 77-88

Garrido, N. (1988). Agaricales s.l und ihre in den Nothofagus - Wäldern mittelchiles. Bibliotheca Mycologica Band 120. Ed. J. Cramer. Berlín, Stuttgart.

Hesler, L. \& Smith, A. (1979). North American species of Lactarius. The University of Michigan press.
Horak, E. (1977). New and rare Boletus from Chile. Bol. Soc. Argen. Bot. 18: 97-109

Horak, E. (1979). Flora criptogámica de Tierra del Fuego. Orden Agaricales. Tomo 11 (6): 1-524. Buenos Aires, Argentina.

Lazo, W. (2001). Hongos de Chile. Atlas Micológico. Facultad de Ciencias U. de Chile. Santiago

Moreno, G.; Manjon, J. L. \& Zugaza, A. (1986). La guía de Incafo de los hongos de la Península Ibérica. Vols. I y II. Incafo. Madrid.

Peredo, H.; Oliva, M. \& Huber, A. (1983). Environmental factors determinig the distribution of Suillus luteus, fructification in Pinus radiata grazing-forest plantations. Plant and Soil 71: 363-370

Reijnders, A. \& Stalpers, J. (1992). The development of the hymenophoral trama in the Aphyllophorales and Agaricales. Studies in Mycology 34. Centraalbureau Voor Schimmelculture Baarn and Delft.

Singer, R. (1969). Mycoflora Australis. Beih. Nova Hedwigia 29: 1-406

Singer, R. (1986). The Agaricales in modern taxonomy. Koeltz Scientific books.

Smiths, A. \& Thiers, H. (1971). The Boletes of Michigan. The University of Michigan press.

Valenzuela, E.; Moreno, G. \& Grinbergs, J. (1992). Algunas Boletaceas que fructifican en el sur de Chile. Bol. Micol. 7: 1-15 